\title{
LQB-118 compound inhibits migration and induces cell death in glioblastoma cells
}

\author{
PAULA SABBO BERNARDO ${ }^{1}$, GUSTAVO HENRIQUE C. GUIMARÃES ${ }^{1,2}$, FERNANDA COSTAS C. DE FARIA ${ }^{1}$, \\ GABRIEL M. DA CUNHA LONGO ${ }^{1,3}$, GISELLE P. DE FARIA LOPES ${ }^{1}$, \\ CHAQUIP DAHER NETTO ${ }^{4}$, PAULO R.R. COSTA $^{5}$ and RAQUEL C. MAIA ${ }^{1}$
}

\begin{abstract}
${ }^{1}$ Laboratory of Cellular and Molecular Hemato-Oncology, Program of Molecular Hemato-Oncology, Brazilian National Cancer Institute (INCA); ${ }^{2}$ Post Graduate Program in Oncology, INCA, Rio de Janeiro, RJ 20230-130; ${ }^{3}$ Federal University of Rio de Janeiro (UFRJ), Rio de Janeiro, RJ 21941-902; ${ }^{4}$ Chemistry Laboratory, Federal University of Rio de Janeiro (UFRJ), Macaé Campus, Rio de Janeiro, RJ 27930-560; ${ }^{5}$ Bioorganic Chemistry Laboratory, Natural Products Research Institute (IPPN), Rio de Janeiro Federal University (UFRJ), Rio de Janeiro, RJ 21941-599, Brazil
\end{abstract}

Received May 20, 2019; Accepted September 20, 2019

DOI: $10.3892 /$ or.2019.7402

\begin{abstract}
Glioblastoma (GBM) is the most frequent malignant brain tumor. It represents the most aggressive astrocytoma with an overall survival of 14 months. Despite improvements in surgery techniques, radio- and chemotherapy, most patients present treatment resistance, recurrence and disease progression. Therefore, development of effective alternative therapies is essential to overcome treatment failure. The purpose of the study was to evaluate the antitumoral activity of the synthetic compound LQB-118, in vitro. Monolayer and three-dimensional (3D) cell culture systems of human-derived GBM cell lines were used to evaluate the effect of LQB-118 on cell viability, cell death and migration. LQB-118 reduced cell viability as determined by MTT and trypan blue exclusion assays and promoted apoptosis in monolayer cell lines with an intrinsic temozolomide (TMZ)-resistance profile. In 3D culture models, LQB-118 reduced cell viability as evaluated by APH assay and inhibited cell migration while the TMZ resistance profile was maintained. Moreover, LQB-118 reduced p38 and AKT expression and phosphorylation, whereas it reduced only the phosphorylated ERK1/2 form. LQB-118 reduced p38 and NRF2 expression, an axis that is associated with TMZ resistance, revealing a mechanism to overcome resistance. LQB-118 also demonstrated an additional effect when combined with ionizing radiation and cisplatin. In conclusion, the present data demonstrated that LQB-118 maintained its effectiveness in a
\end{abstract}

Correspondence to: Professor Raquel C. Maia, Laboratory of Cellular and Molecular Hemato-Oncology, Program of Molecular Hemato-Oncology, Brazilian National Cancer Institute (INCA), Praça da Cruz Vermelha 23, Rio de Janeiro 20230-130, Brazil E-mail: rcmaia@inca.gov.br

Key words: glioblastoma, antitumoral compound, LQB-118, temozolomide, 3D culture models, spheroids
3D cell conformation, which shares more similarities with the tumor mass. LQB-118 is a promising agent for GBM treatment as monotherapy and associated with radiotherapy or cisplatin. Its effect is associated with inhibition of GBM-related survival signaling pathways.

\section{Introduction}

Glioblastoma (GBM) is the most malignant primary brain tumor in humans. It is highly aggressive and heterogeneous, remaining a major therapeutic challenge, since patients have a mean overall survival (OS) of only 14 months and a progression-free survival (PFS) time of 7-10 months (1). First-line postsurgical therapy for GBM consists of temozolomide (TMZ) combined with regional fractionated radiotherapy followed by adjuvant TMZ (2,3). The introduction of TMZ as first-line treatment enhanced the quality of life and OS of patients (2). However, TMZ resistance has emerged and there is no standard of care treatment for recurrence (3). The use of chemotherapy for relapse cases yields response rates below $15 \%(1,4)$. New therapeutic strategies to overcome treatment failure and improve the OS of GBM patients are required. In this context, the synthetic pterocarpanquinones are promising compounds (5). Among them, LQB-118 has been revealed to have antitumor activity in myeloid leukemia cells, promoting cell death regardless of their resistance mechanisms (5-8). Likewise, LQB-118 cytotoxicity was demonstrated in prostate cancer cells resistant to androgen-based therapy, in vitro and in vivo $(9,10)$. The basic chemical property of the compound may involve reduction of the paranaphtoquinone moiety in the mitochondria, producing ROS or a reaction product that acts like an alkylating agent (5). A comprehensive toxicology study demonstrated good tolerability of LQB-118 as confirmed by the absence of clinical, biochemical, or hematological parameter changes (11). Furthermore, the dose that induced subacute toxicity was 5 times higher than the therapeutic dose used to treat prostate xenografts in nude mice $(11,12)$. LQB-118 also induced reactive oxygen species (ROS) formation and apop- 
totic cell death by the intrinsic and endoplasmic reticulum stress pathways $(10,12)$. The compound regulated $\mathrm{NF}-\kappa \mathrm{B}$, FOXO3a and FOXM1 transcription factors without toxicity to mouse bone marrow-derived cells $(8,13)$. MAPKs and Akt pathways are regulators of the aforementioned transcriptional factors and have been linked to GBM heterogeneity, invasiveness and treatment resistance (14-16). Therefore, understanding LQB-118 effects and mechanism of action has the potential to improve therapeutic strategies. The present study evaluated the antitumor activity of LQB-118 as a monotherapy and combined with radiotherapy or chemotherapy in GBM monolayer and spheroid models.

\section{Materials and methods}

Cell lines. Human GBM cell lines, U251-MG, T98G and A172 were kindly provided by Dr Vivaldo Moura-Neto. Cells were maintained in Dulbecco's Modified Eagle's Medium: Nutrient Mixture F-12 (DMEM-F12; Gibco ${ }^{\circledR}$; Thermo Fisher Scientific, Inc.) supplemented with penicillin $(100 \mathrm{UI} / \mathrm{ml})$, streptomycin $(0.1 \mathrm{mg} / \mathrm{ml})$ and $10 \%$ fetal bovine serum (FBS) as a monolayer at $37^{\circ} \mathrm{C}$ with $5 \% \mathrm{CO}_{2}$. Cells were tested and authenticated by DNA (STR) profiling and periodically tested for Mycoplasma. Cells seeded at $3 \times 10^{4}$ cells $/ \mathrm{cm}^{2}$ were used for all 2D experiments. Cells were allowed to adhere to culture flasks overnight before drug treatments and experimental analysis.

Compound handling. The synthetic compound, LQB-118 was developed by the Laboratory of Bioorganic Chemistry at the Natural Products Research Institute (IPPN) of the Federal University of Rio de Janeiro (UFRJ) (5). LQB-118 and TMZ (ITF chemical, Brazil) were stocked in powder form while cisplatin was stocked as a solution, all at room temperature (RT). TMZ was diluted in dimethyl sulfoxide (DMSO; cat. no. D2650; Sigma-Aldrich ${ }^{\circledR}$; Merck KGaA) immediately before use. LQB-118 was diluted in DMSO and stored at $-20^{\circ} \mathrm{C}$ for no longer than two weeks. DMSO was used as a vehicle control for all experiments.

MTT assay. Cells were incubated with different concentrations of TMZ $(5.0,25.0,50.0,100.0,250.0$ and $500.0 \mu \mathrm{M})$ or LQB-118 $(3.0,6.0,9.0$ and $12.0 \mu \mathrm{M})$ for 24,48 and $72 \mathrm{~h}$. 3-(4,5-Dimethylthiazol-2-yl)-2,5-diphenyltetrazolium bromide (MTT; cat. no. 20395; SERVA) was added $4 \mathrm{~h}$ before the end of incubation. The formazan crystals formed were eluted in DMSO and the absorbance was measured at $492 \mathrm{~nm}$ using a Beckman Coulter DTX800 multimode spectrophotometer. Optical density of control cells was considered as $100 \%$ of viability. Three independent experiments were performed with four replicates for each experimental condition.

Trypan blue exclusion assay. Cells were treated with TMZ (50.0 and $100.0 \mu \mathrm{M})$ or LQB-118 $(6.0$ and $12.0 \mu \mathrm{M})$ for 24 and $48 \mathrm{~h}$. After treatment, the supernatant was collected, cells were washed with phosphate-buffered saline (PBS) and detached using trypsin $0,125 \%$ (cat. no. 27250018; GIBCO ${ }^{\circledR}$; Thermo Fisher Scientific, Inc.). Trypan blue was added to all collected cells (floating and detached by trypsin cells). Cells stained blue (trypan blue-positive cells) and not stained blue (trypan blue-negative cells) were counted under an optical micro- scope. The percentage of trypan blue-negative cells (assumed as viable cells) was calculated relative to the control, which was considered $100 \%$. Additionally, the amount of trypan blue-positive cells (assumed as dead cells) was calculated relative to the total number of cells present in each condition.

Annexin V/Propidium iodide (PI) assay. Cells were treated with TMZ (50.0 and $100.0 \mu \mathrm{M})$ or LQB-118 $(6.0$ and $12.0 \mu \mathrm{M})$ for 24 and $48 \mathrm{~h}$. After treatment, the cells were washed with PBS and detached from culture flasks using trypsin $0,125 \%$ (Gibco ${ }^{\circledR}$; Thermo Fisher Scientific, Inc.). Then, all collected cells (floating and detached by trypsin cells) were centrifuged (700 x g) and incubated with PBS supplemented with $2 \%$ bovine serum albumin (BSA) for $30 \mathrm{~min}$ at RT. After washing, the cells were incubated with Annexin V-Alexa Fluor ${ }^{\circledR} 488$ conjugated (cat. no. A13201; Invitrogen ${ }^{\mathrm{TM}}$; Thermo Fisher Scientific, Inc.) for $15 \mathrm{~min}$ in the dark at RT. PI was added before event acquisition and used to differentiate non-apoptotic cell death (Annexin $\mathrm{V}^{-} / \mathrm{PI}^{+}$). The drug-induced apoptotic rate (Annexin $\mathrm{V}^{+} / \mathrm{PI}^{-}$and Annexin $\mathrm{V}^{+} / \mathrm{PI}^{+}$) was compared to the control (spontaneous apoptosis). Events $(10,000)$ were acquired using Cyan ADP (Beckman Coulter) and data were analyzed using Summit 4.3 software (Beckman Coulter Inc.). Three independent experiments were performed.

Western blot analysis. Cells were treated with TMZ (50.0 and $100.0 \mu \mathrm{M})$ or LQB-118 $(6.0$ and $12.0 \mu \mathrm{M})$ for $24 \mathrm{~h}$. After detachment by trypsin and washing with PBS, the cells were lysed with Cell Extraction Buffer (cat. no. FNN0011; Invitrogen $^{\mathrm{TM}}$; Thermo Fisher Scientific, Inc.) according to the manufacturer's instructions. Protein concentration was determined by Lowry method using a commercial Kit (DC ${ }^{\mathrm{TM}}$ Protein Assay; cat. no. 500-0116; Bio-Rad Laboratories, Inc.). Western blot analysis using $30 \mu \mathrm{g}$ of protein was performed with $12 \%$ SDS-PAGE and transferred to Hybond-P membranes (cat. no. 29047575; GE Healthcare ${ }^{\circledR}$ ) and immunoblotted. The membranes were blocked with nonfat milk 5\% for $1 \mathrm{~h}$, washed with Tris-buffered saline (TBS)-Tween $0.2 \%$, and incubated with primary antibodies (Abs) diluted in nonfat milk overnight at $4^{\circ} \mathrm{C}$. The following day, the membranes were incubated with secondary antibodies for $1 \mathrm{~h}$ at RT. Primary antibodies used were anti-Akt (1:1,000 dilution; rabbit polyclonal antibody (pAb); cat. no. 9272), anti-p-Akt (1:1,000 dilution; phosphorylation at Ser473; rabbit pAb; cat. no. 9271), anti-p38 MAPK (1:1,000 dilution; rabbit pAb; cat. no. 9212), anti-p-p38 MAPK (1:1,000 dilution; phosphorylation site: T180/Y182; rabbit pAb; cat. no. 9211), anti-ERK1/2 (p44/42MAPK) (clone 137F5; 1:1,000 dilution; rabbit monoclonal antibody (mAb); cat. no. 4695; all from Cell Signaling Technology, Inc.), anti-p-ERK1/ERK2 (clone 15H10L7; 1:1,000 dilution; phosphorylation at Thr185, Tyr187; rabbit mAb; cat. no. 700012; ABfinity ${ }^{\mathrm{TM}}$; Invitrogen ${ }^{\mathrm{TM}}$; Thermo Fisher Scientific, Inc.), anti-NRF2 (clone C-20; 1:1,000 dilution; rabbit pAb; sc-722; Santa Cruz Biotechnology, Inc.), anti-pro-caspase-7 (clone MCH3101; 1:1,000 dilution; cat. no. MAB823; R\&D Systems $\left.{ }^{\circledR}\right)$, anti-PARP (1:1,000 dilution; rabbit pAb; cat. no. 9542 Cell Signaling Technology ${ }^{\circledR}$, Inc.) and anti-HSC70 (1:1,000 dilution; mouse mAb (B-6); cat. no. sc-7298; Santa Cruz Biotechnology, Inc.). Secondary antibodies were anti-mouse IgG and anti-rabbit IgG-HRP 
conjugated (1:20,000 dilution; Amersham ECL ${ }^{\mathrm{TM}}$ Western blotting Detection Reagents; GE Healthcare ${ }^{\circledR}$; cat. nos. respectively, A9169 and A9044). ECL Prime Detection System (cat. no. RPN2236; Amersham Biosciences ${ }^{\mathrm{TM}}$; GE Healthcare) was applied for protein detection by C-Digit ${ }^{\mathrm{TM}}$ Blot Scanner, generating images in Image Studio Lite software v3.1 (LI-COR Biosciences $\left.{ }^{\circledR}\right)$. Three independent experiments were performed and analyzed qualitatively. Protein expression was normalized by HSC70 expression.

Spheroid model three-dimensional (3D) culture. Multicellular tumor spheroids were formed from the cell lines U251-MG and A172 using the liquid-overlay technique (17). Cells (200 $\mu \mathrm{l})\left(10^{4} \mathrm{cells} / \mathrm{ml}\right)$ in DMEM-F12 medium supplemented with $10 \%$ of FBS were seeded in a 96-well flat bottom plate previously coated with $1.5 \%$ agarose type II (cat. no. A6877; Sigma-Aldrich ${ }^{\circledR}$; Merck KGaA). The outer wells were filled with PBS to avoid evaporation. Cells were cultured for 4 days until tightly aggregated spheroids of $\sim 300 \mu \mathrm{m}$ of diameter were fully formed.

Acid phosphatase (APH) assay (3D culture). Cell viability in spheroids was assessed using the APH (cat. no. 71768; Sigma-Aldrich ${ }^{\circledR}$; Merck KGaA) assay (18). Fully formed spheroids were treated with different concentrations of LQB-118 (3.0, 6.0, 9.0 and 12.0 $\mu \mathrm{M})$ or TMZ $(25.0,50.0,100.0$ and $200.0 \mu \mathrm{M}$ ) for $72 \mathrm{~h}$. Then, spheroids were transferred to a 96-well plate without an agarose coat and washed twice to remove the medium. Substrate solution containing nitrophenylphosphate $(2 \mathrm{mg} / \mathrm{ml})$ and Triton X-100 in citrate buffer $(0.1 \mathrm{M})$, diluted in PBS, was added and incubated for $90 \mathrm{~min}$ in an incubator at $37^{\circ} \mathrm{C}$. Then, $\mathrm{NaOH}(1 \mathrm{M})$ was added and the absorbance measured at $405 \mathrm{~nm}$ using Beckman Coulter DTX800 multimode spectrophotometer. Optical densities were normalized using the absorbance of spheroids treated with DMSO as a control. The experiment was repeated at least 3 times with 8 replicates each.

Migration assay ( $3 D$ culture). Spheroids were transferred to a 24-well plate coated with $0.1 \%$ gelatin and culture medium containing LQB-118 $(1.0$ and $3.0 \mu \mathrm{M})$ or TMZ $(25.0,50.0$, 100.0 and $200.0 \mu \mathrm{M}$ ). Migration was assessed after 24,48 and $72 \mathrm{~h}$. To avoid cell proliferation, a medium containing only $2 \%$ FBS was used in the experiments, carried out in triplicate. Quantification of the migration index was performed manually using the software ImageJ v.1.5 (19) and the migration index was calculated using the following formula: (Area of the bigger halo)/(area of the spheroid at $0 \mathrm{~h}$ ).

Drug interaction analysis. U251-MG and A172 cells were treated with LQB-118 $(3.0$ and $6.0 \mu \mathrm{M})$ combined with ionizing radiation (4 Gy), TMZ (50 and $100 \mu \mathrm{M}$ ) or cisplatin (CDDP, 3.0 and $30.0 \mathrm{nM}$ ) for $48 \mathrm{~h}$. Cell viability and cell death were evaluated by MTT, trypan blue exclusion and Annexin V/PI assays as aforementioned. The significance of concurrent combination treatment by MTT was evaluated by combination index (CI) value calculated by CompuSyn software (ComboSyn, Inc; www.combosyn.com) derived from the Chou-Talalay method $(20,21)$. Statistical analysis of trypan blue exclusion and Annexin V/PI were realized by GraphPad Prism software version 5.0 (GraphPad Software ${ }^{\circledR}$ Incorporated) as the limited number of conditions did not allow synergism analysis.

Statistical analysis. Statistical and graphical information was determined using the GraphPad Prism software version 5.0. One-way ANOVA test followed by Bonferroni post hoc test was used to compare treatment groups. Significant variance of ANOVA F-values ranged from 4.63 to 49.61. DMSO was used as a reference group to determine statistical significance and P-values were reported at $95 \%$ confidence intervals. A P-value of $<0.05$ was considered to indicate a statistically significant difference and denoted as $\mathrm{P}<0.05$. Statistical significance in the figures was represented by ${ }^{*} \mathrm{P}<0.05,{ }^{* *} \mathrm{P}<0.01$ and ${ }^{* * * *} \mathrm{P}<0.001$. The results are presented as the mean of independent experiments \pm standard error.

\section{Results}

LQB-118 reduces cell viability and induces apoptosis in three GBM cell lines. U251-MG, A172 and T98G cells were treated with different concentrations of LQB-118 to assess cell line sensibility. Initially, LQB-118 reduced cell viability by MTT of all cell lines (Fig. 1). LQB-118 6.0 $\mu \mathrm{M}$ significantly reduced U251-MG and A172 cell viability after 48 and $72 \mathrm{~h}$, but not of T98G cells (Fig. 1A-C). Higher concentrations of LQB-118 (9.0 and $12.0 \mu \mathrm{M})$ reduced cell viability by almost $90 \%$ after 48 and $72 \mathrm{~h}$ of treatment in U251-MG and A172 (Fig. 1A and B). In T98G cells, LQB-118 9.0 and $12.0 \mu \mathrm{M}$ reduced cell viability by 60 and $80 \%$, respectively (Fig. 1C). Therefore, a concentration that had a moderate effect $(6.0 \mu \mathrm{M})$ and one $(12.0 \mu \mathrm{M})$ that demonstrated a high reduction of cell viability were selected to perform further experiments for 24 and $48 \mathrm{~h}$ of treatment. Corroborating the viability results, LQB-118 6.0 and $12.0 \mu \mathrm{M}$ reduced cell viability by approximately 50 and $80 \%$, respectively, as quantified by trypan blue exclusion assay (Fig. 1D). However, only $12.0 \mu \mathrm{M}$ induced cell death (Fig. 1E). Furthermore, cell detachment from culture flasks was observed in all cell lines after treatment with $12.0 \mu \mathrm{M}$, but not in the controls and LQB-118 $6.0 \mu \mathrm{M}$ groups (Fig. S1). Apoptotic cell death induction by LQB-118 was evaluated by Annexin V/PI labeling (Fig. 2). In U251-MG and T98G cells, only $12.0 \mu \mathrm{M}$ induced significant $60 \%$ Annexin $\mathrm{V}$ labeling after $48 \mathrm{~h}$ (Fig. 2A and C). A172 cells were sensitive to 9.0 and $12.0 \mu \mathrm{M}$, presenting 40 and $80 \%$ of Annexin $\mathrm{V}$ labeling after $48 \mathrm{~h}$, respectively (Fig. 2B). The collective results demonstrated the antitumoral activity of LQB-118 against three GBM-derived cell lines.

Temozolomide has a minor cytotoxic effect in GBM cell lines. U251-MG, A172 and T98G sensibility to first line chemotherapy were evaluated by MTT. The highest TMZ concentration, $500 \mu \mathrm{M}$, reduced cell viability in U251-MG cells while no effect was observed in A172 and T98G cells (Fig. 3A-C). In the studied conditions, the cell lines demonstrated a resistance profile to TMZ while they were sensitive to LQB-118. The conventional dose schedule of TMZ reaches $\sim 50 \mu \mathrm{M}$ in plasma (22). Therefore, 50.0 and $100.0 \mu \mathrm{M}$ were selected for further experiments in U251-MG cells since this cell line has been revealed to be tumorigenic in nude mice and resistant to TMZ by p38/NRF2 axis activation $(15,23)$. 
A

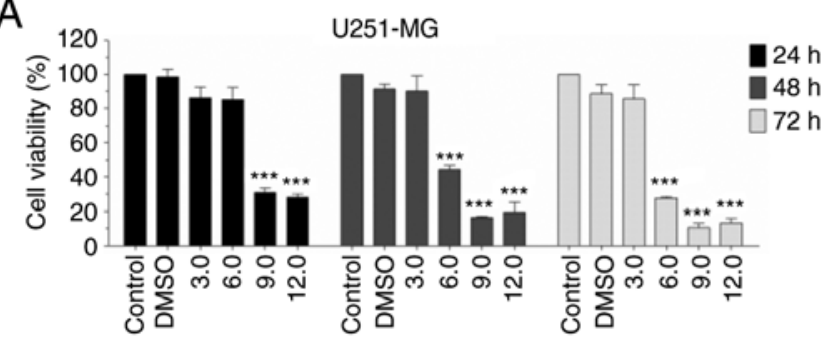

B
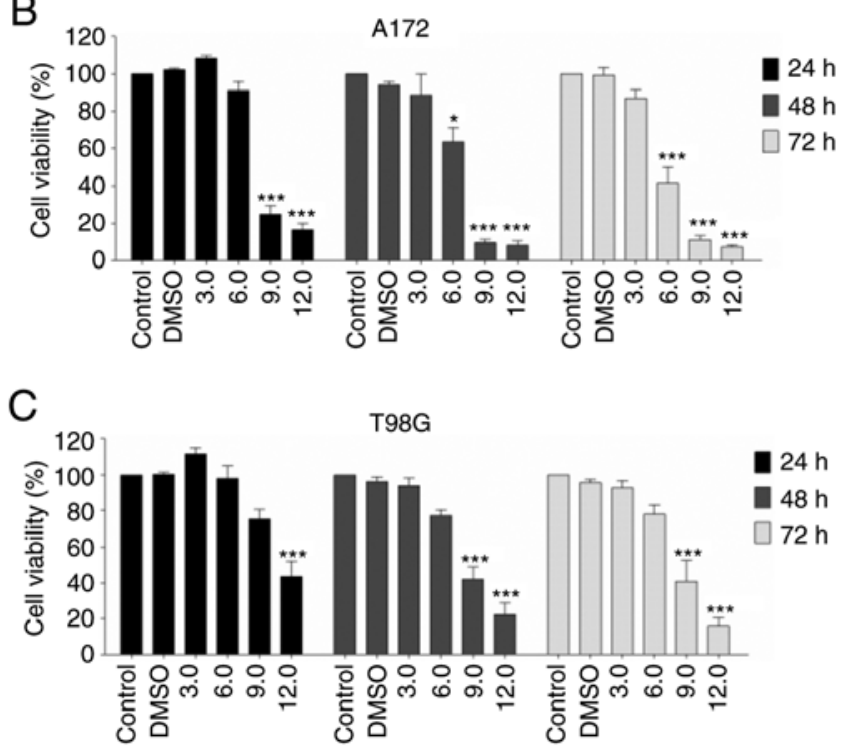

D

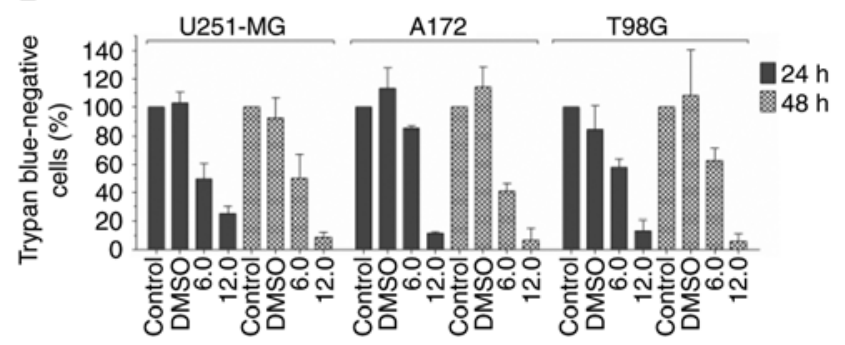

$\mathrm{E}$

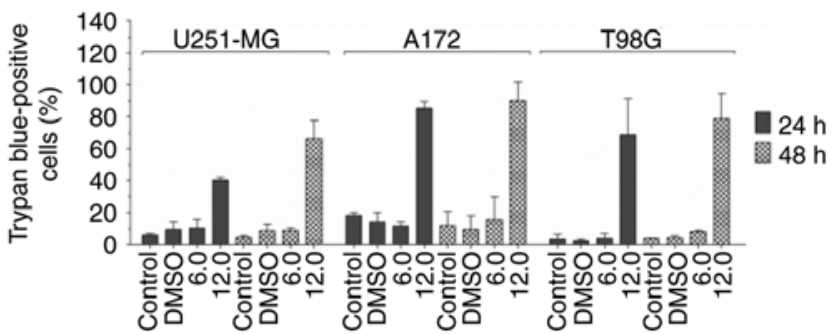

Figure 1. Effect of LQB-118 on GBM cell line viability. Percentage of (A) U251-MG, (B) A172 and (C) T98G viable cells after screening of increasing concentrations of LQB-118 evaluated by MTT. Mean of three independent experiments \pm SEM. ${ }^{*} \mathrm{P}<0.05 ;{ }^{* * * *} \mathrm{P}<0.001$. (D) Percentage of trypan blue-negative cells relative to the control and (E) percentage of trypan blue-positive cells in each treatment condition. Mean of two independent experiments \pm SD. GBM, glioblastoma.

TMZ did not induce cell detachment from culture flasks, nor cell death by trypan blue exclusion assay or Annexin V labeling, but induced a slight reduction in pro-caspase-7 (Fig. 3D-G). Furthermore, treatment with LQB-118 induced caspase-7 activation as suggested by the reduced expression of its pro-caspase form (Fig. 3G). LQB-118 also promoted PARP cleavage in U251-MG and A172 cells (Fig. 5). These results corroborated apoptosis induction by the compound LQB-118.

$L Q B-118$ is cytotoxic and reduces cell migration in spheroids of GBM cell lines. A 3D cell culture system is a great tool for drug screening (24). LQB-118 antineoplastic activity was also evaluated in 3D cultures. LQB-118 concentrations of 9.0 and $12.0 \mu \mathrm{M}$ significantly reduced U251-MG spheroid viability, while TMZ did not (Fig. 4A). Cell lines maintained the resistance to TMZ observed in the monolayer and LQB-118 maintained its cytotoxicity, overcoming TMZ resistance. GBM is highly infiltrative, therefore, the ability of LQB-118 to impair cell migration was evaluated in a 3D culture. Lower LQB-118 concentrations were used $(1.0$ and $3.0 \mu \mathrm{M})$ to guarantee that the effect observed was derived exclusively from migration inhibition and not an artefact of proliferation inhibition or death induction. The results revealed that LQB-118 significantly reduced the migratory potential of GBM cells while TMZ had no effect, corroborating the LQB-118 effectiveness in GBM cells (Fig. 4B and C). A similar profile was observed for A172 spheroids (Fig. 4D-F).
Cytotoxic effect of LQB-118 is associated with downregulation of survival pathways. The PI3K/Akt and MAPK pathways are markedly relevant in GBM invasion, progression and treatment resistance $(14,25,26)$. Considering the effect of LQB-118 on cell migration and viability, and to further understand its mechanism, Akt, ERK and p38 pathways were investigated by western blotting. TMZ 50.0 and $100.0 \mu \mathrm{M}$ did not regulate p38 and total Akt and phosphorylated protein levels, while it slightly reduced ERK phosphorylation in U251-MG cells (Fig. 5A). Conversely, $12.0 \mu \mathrm{M}$ of LQB-118 reduced total protein expression and phosphorylated levels of p38 and Akt and ERK phosphorylation, while the levels of total ERK were not reduced (Fig. 5A). Furthermore, LQB-118 reduced NRF2 expression and concurrently inhibited MAPK and Akt pathways, reinforcing the potential of LQB-118 against this heterogeneous disease. As aforementioned for the 3D assays, a similar profile was observed for the A172 cell line (Fig. 5B).

Synergic effect of LQB-118 and cisplatin reduces viability and increases apoptosis. GBM patients present resistance, disease progression and recurrence. Salvage therapies are not effective and LQB-118 downregulates radio- and chemoresistance-associated pathways. Therefore, its effect in association with DNA damage inducers, ionizing radiation, CDDP and TMZ was evaluated, in order to obtain a possible less toxic and more effective treatment approach. First, LQB-118 6.0 
A

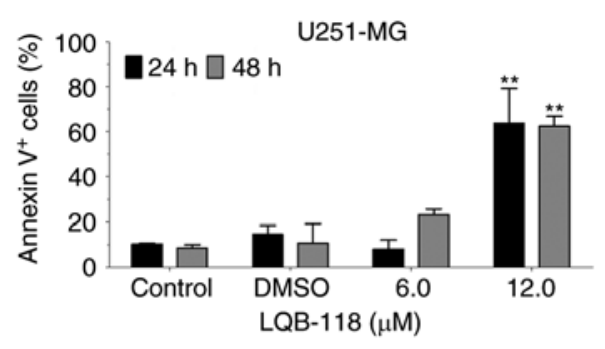

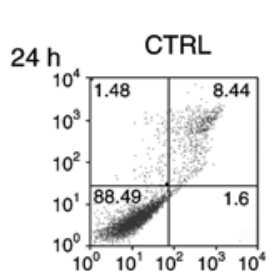

$48 \mathrm{~h}$

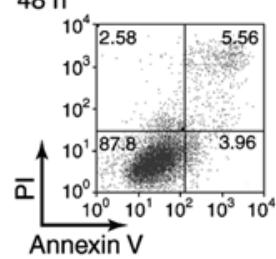

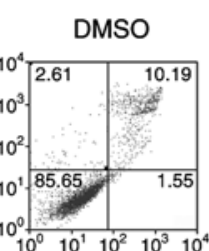

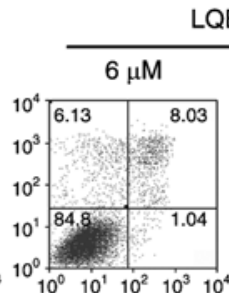

LQB-118
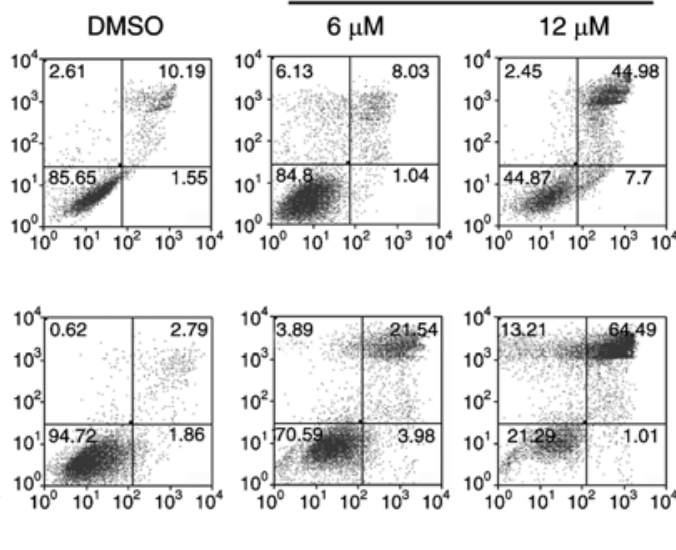
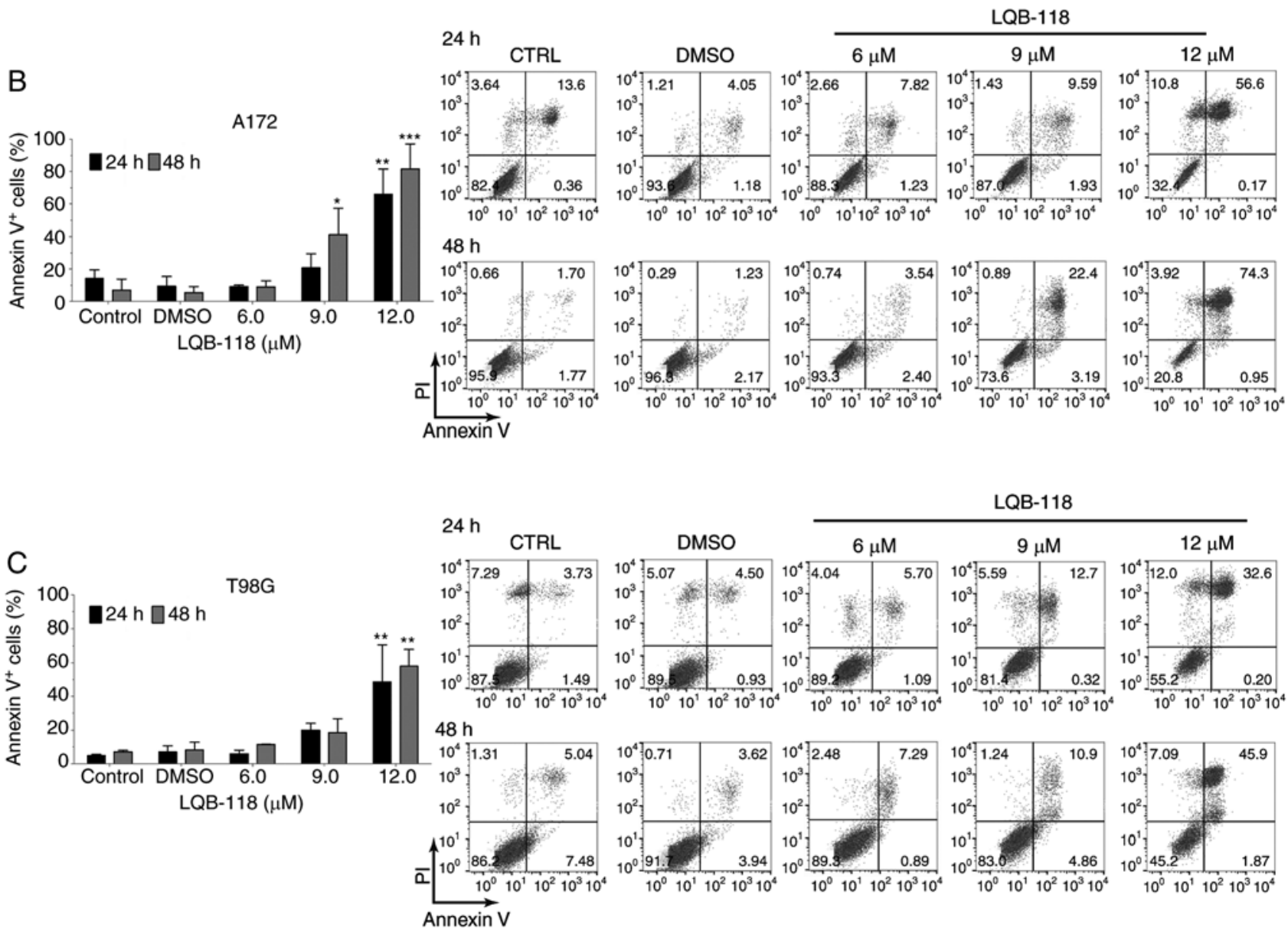

$48 \mathrm{~h}$
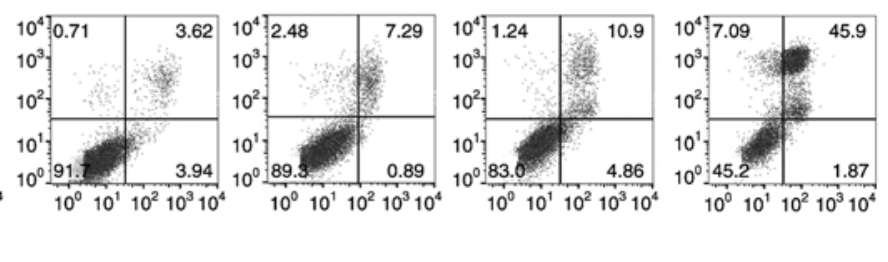

Figure 2. Effect of LQB-118 on GBM cell line apoptosis. Percentage of Annexin V-positive cells (Annexin $\mathrm{V}^{+} / \mathrm{PI}^{-}+\mathrm{AnnexinV}^{+} / \mathrm{PI}^{+}$) after LQB-118 treatment in (A) U251-MG, (B) A172 and (C) T98G cells evaluated by flow cytometry. Representative dot plots (in the right column) and graphic bars (in the left column) with the mean of three independent experiments $\pm \mathrm{SD}$. One-way ANOVA and Bonferroni post hoc test: ${ }^{*} \mathrm{P}<0.05 ;{ }^{* * *} \mathrm{P}<0.01 ;{ }^{* * * *} \mathrm{P}<0.001$. ANOVA F-values were 49.51, 25.38 and 24.12 after treatment for $48 \mathrm{~h}$ in U251-MG, A172 and T98G cells, respectively. GBM, glioblastoma.

or TMZ $50.0 \mu \mathrm{M}$ where concurrently used with ionizing radiation. In U251-MG cells, $6.0 \mu \mathrm{M}$ of LQB-118 combined with 4 Gy significantly reduced cell viability by $\sim 40 \%$ as determined by trypan blue exclusion assay in comparison to isolated treatments, while TMZ $50.0 \mu \mathrm{M}$ with 4 Gy reduced cell viability by $\sim 27 \%$ (Fig. 6A). However, this effect was not observed by Annexin $\mathrm{V}$ labeling for both treatment strategies (Fig. 6B), demonstrating that LQB-118 and TMZ have similar results when combined with radiotherapy. In A172 cells, 4 Gy of ionizing radiation alone reduced cell viability and no additional effect was observed after combination with LQB-118 or TMZ in these cells (Fig. 6C and D).

Subsequently, LQB-118 was concurrently treated with CDDP or TMZ (Fig. 7). Previous data from our group demonstrated that cisplatin $3.0 \mu \mathrm{M}$ had no effect while $30.0 \mu \mathrm{M}$ reduced cell viability by $50 \%$ as determined by MTT (unpublished data). Therefore, these concentrations were selected for combination experiments. In U251-MG cells, LQB-118 (3.0 

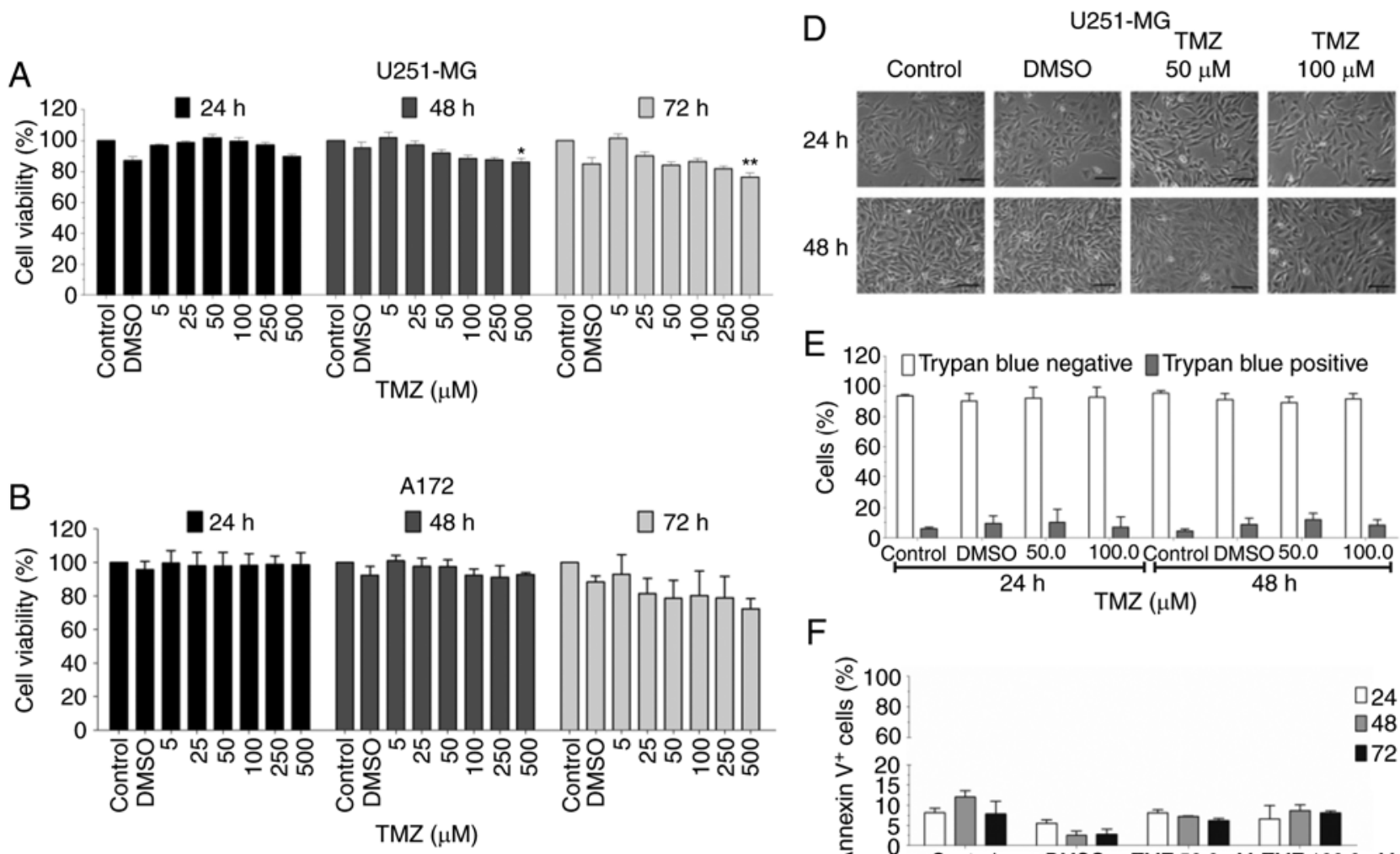

F
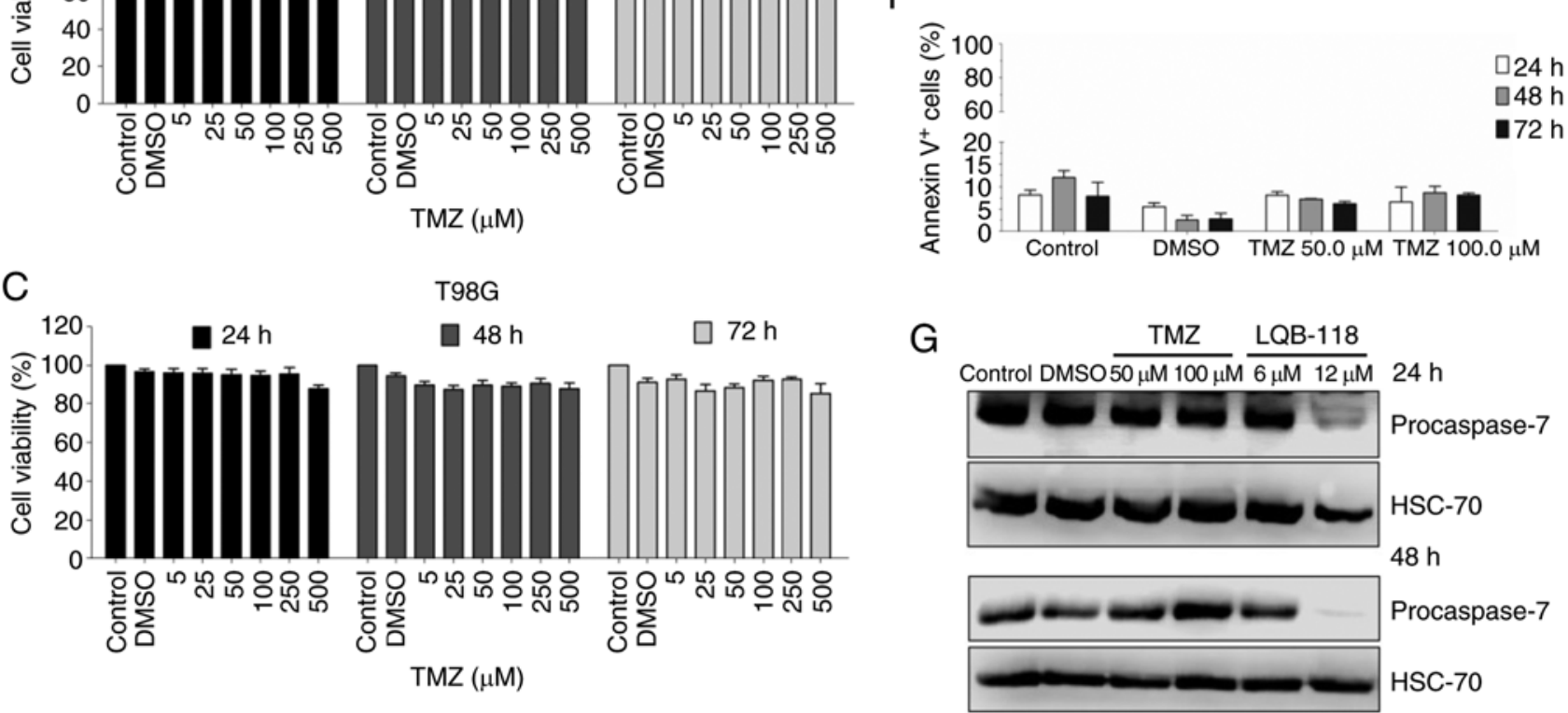

Figure 3. Effect of TMZ on GBM cell viability and cell death. Percentage of (A) U251-MG, (B) A172 and (C) T98G viable cells after treatment with increasing concentrations of TMZ evaluated by MTT. Mean of three independent experiments \pm SEM. ${ }^{*} \mathrm{P}<0.05 ;{ }^{* *} \mathrm{P}<0.01$. (D) Contrast phase photomicrography, magnified 10 times, of U251-MG cells after treatment with TMZ. Scale bar, $100 \mu \mathrm{m}$ (E) Percentage of trypan blue-negative cells (cell viability) and trypan blue-positive cells (cell death) in each treatment condition. (F) Percentage of U251-MG Annexin V-positive cells (Annexin $\mathrm{V}^{+} / \mathrm{PI}^{-}+\mathrm{Annexin}^{+} / \mathrm{PI}^{+}$) after TMZ treatment evaluated by flow cytometry. (G) Procaspase-7 expression evaluated after U251-MG cells were treated with LQB-118 or TMZ. Images represent two independent experiments. TMZ, temozolomide; GBM, glioblastoma.

and $6.0 \mu \mathrm{M})$ demonstrated a synergic effect with CDPP $(3.0$ and $30.0 \mu \mathrm{M})$ and TMZ (50.0 and $100.0 \mu \mathrm{M})$ as revealed by MTT after $48 \mathrm{~h}$ (Fig. 7A and B; Table SI). The combination of LQB-118 3.0 $\mu \mathrm{M}$ with CDDP $3.0 \mu \mathrm{M}$ significantly enhanced cell death as demonstrated by trypan blue exclusion and Annexin V/PI assays (Fig. 7C and D). Only 20\% of U251-MG cells were viable after combined treatment (data not shown). In A172 cells, LQB-118 3.0 $\mu \mathrm{M}$ demonstrated an additive effect when associated with CDDP 3.0 and $30.0 \mu \mathrm{M}(\mathrm{CI}=1.01$ and $\mathrm{CI}=0.95$, respectively) (Fig. 7E) and an antagonist effect when treated with TMZ (Fig. 7F; Table SI). No significant enhancement in cell death was observed after treatment with CDPP (Fig. 7G) neither with TMZ (Fig. 7H). However, the combination of LQB-118 $(3.0 \mu \mathrm{M})$ with CDDP $(3.0 \mu \mathrm{M})$ reduced cell viability by $\sim 24 \%$ as determined by trypan blue exclusion assay (data not shown). These data indicated that LQB-118 combined with CDDP has a notable effect on cell proliferation, revealing LQB-118 as a potential alternative for a subset of patients with disease recurrence.

\section{Discussion}

GBM is one of the most aggressive tumors and has a five-year survival rate of only $5.1 \%$ (27). TMZ can improve OS, however the majority of patients cannot complete treatment due to toxicity and resistance has become a clinical problem $(2,28,29)$. Despite the therapeutic advances made in recent decades, patients relapse and progress to death. In the context of new drug development to overcome resistance and improve treatment, the present study evaluated the anti- 
A

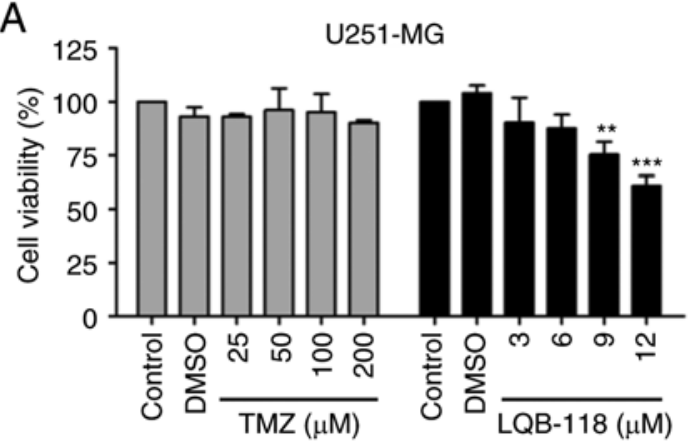

B

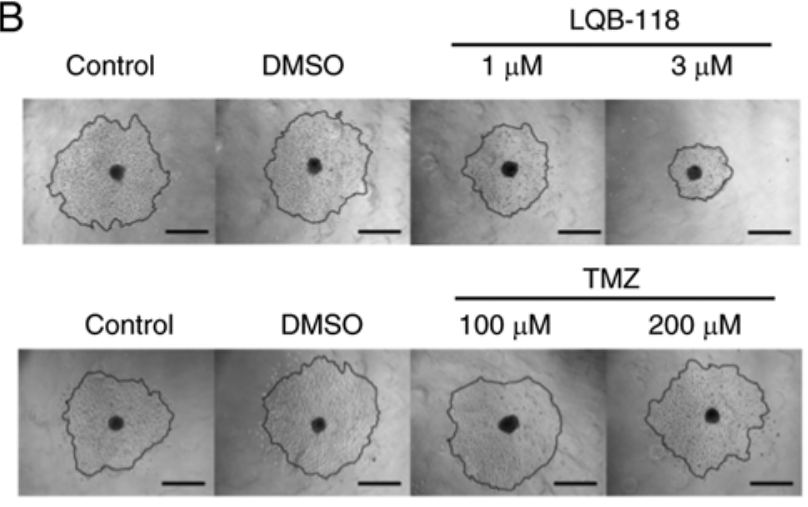

C

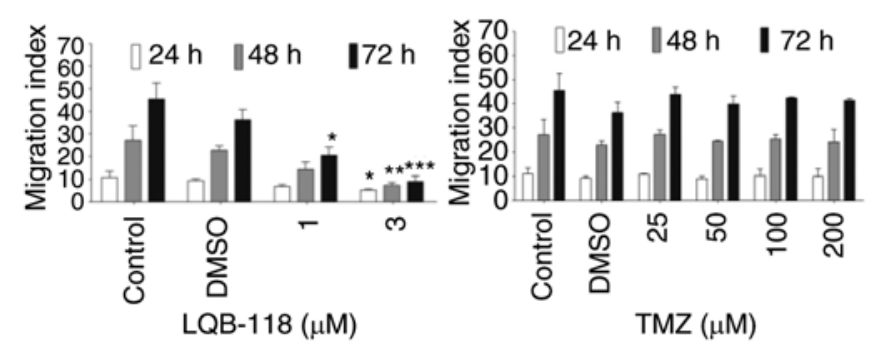

D

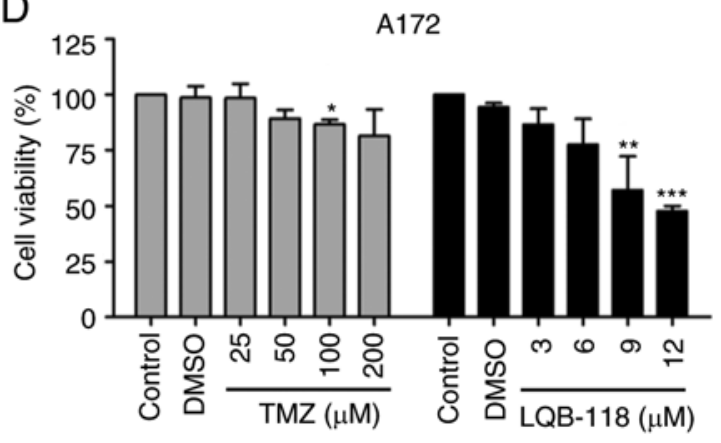

E

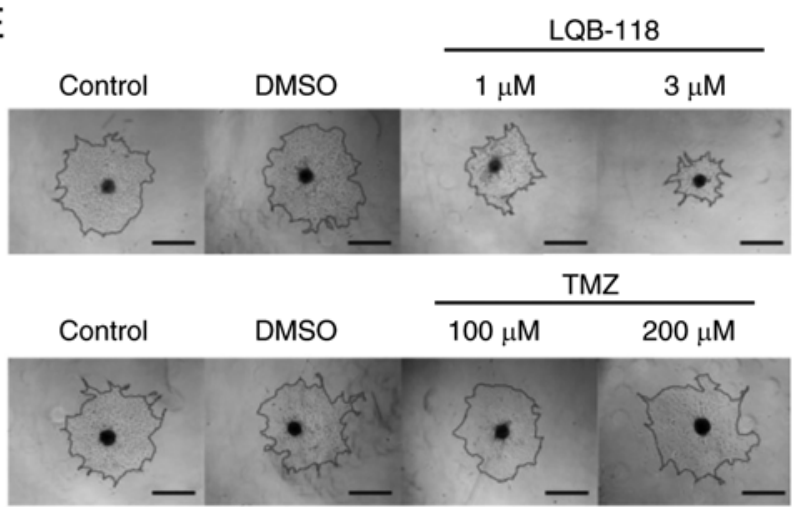

F

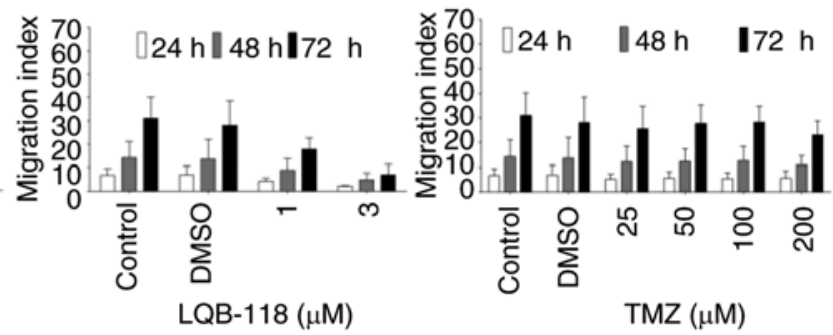

Figure 4. Effect of LQB-118 and TMZ on viability and the migration index of U251-MG and A172 spheroids. Percentage of viable cells in relation to the control after treatment with LQB-118 or TMZ evaluated by APH assay in (A) U251-MG and (D) A172 cells. ANOVA F-values were 18.76 and 18.44 for LQB-118 APH data and 0.45 and 4.63 for TMZ data of U251-MG and A172 cells, respectively. Representative figures of radial migration of spheroids after $72 \mathrm{~h}$ of treatment with LQB-118 and TMZ in (B) U251-MG and (E) A172 cells. At 72 h, ANOVA F-values were 34.85 and 5.98 for LQB-118 migration data and 2.06 and 0.32 for TMZ data of U251-MG and A172 cells, respectively. Graphic bars of the migration index after treatment with LQB-118 and TMZ in (C) U251-MG and (F) A172 cells. Mean of three experiments \pm SEM. Scale bar, $300 \mu \mathrm{m}$. ${ }^{*} \mathrm{P}<0.05 ;{ }^{* *} \mathrm{P}<0.01,{ }^{* * *} \mathrm{P}<0.001$. TMZ, temozolomide; APH, acid phosphatase.

tumoral effect of LQB-118, a synthetic compound. LQB-118 significantly reduced cell viability and induced high levels of apoptosis, while plasmatic concentrations of TMZ did not promote cell death, suggesting an intrinsic resistance of these cells to TMZ. GBM cell line response to TMZ is not uniform in literature mainly due to different treatment procedures and exposure times. In the present study, the same time-points were used for the compound to guarantee an unbiased comparison parameter. Under the studied conditions, LQB-118 induced cell death in different GBM cell lines while TMZ was not efficient in promoting cell death.

Accordingly, LQB-118 induced apoptosis in leukemia cell lines with multidrug resistance (MDR) phenotype $(6,7,12)$ and in androgen-resistant prostate cancer cells (9), demonstrating its great potential to overcome MDR mechanisms in different tumor types. In addition, our group demonstrated the antineoplastic role of LQB-118 in peripheral blood samples obtained from leukemia patients (7), and LQB-118 reduced growth of prostate, melanoma and Erlich tumors, in vitro and in vivo $(9,10,30)$. Moreover, LQB-118 presented no toxicity for bone marrow and spleen cells from healthy mice, primary and secondary organs of the immune system and activated human PBMC (peripheral blood mononuclear cells). These data demonstrate its selectivity for tumor cells and great potential for treatment of patients non-responsive to conventional therapy $(8,30,31)$.

A preclinical study evaluated LQB-118 subacute toxicity and oral administration did not demonstrate clinical signs of toxicity (11). A dose, five times higher than the therapeutic dose induced liver focal necrosis, which was not accompanied by alterations in hepatic enzymes (11). A theoretical analysis of the pharmacokinetic properties of LQB-118 demonstrated it does not violate the Lipinski's rule of five (Ro5) and has a favorable profile, being more likely to progress to market (11). Furthermore, LQB-118 has $96 \%$ probability of crossing the blood brain barrier (BBB) and $100 \%$ probability of human 
A
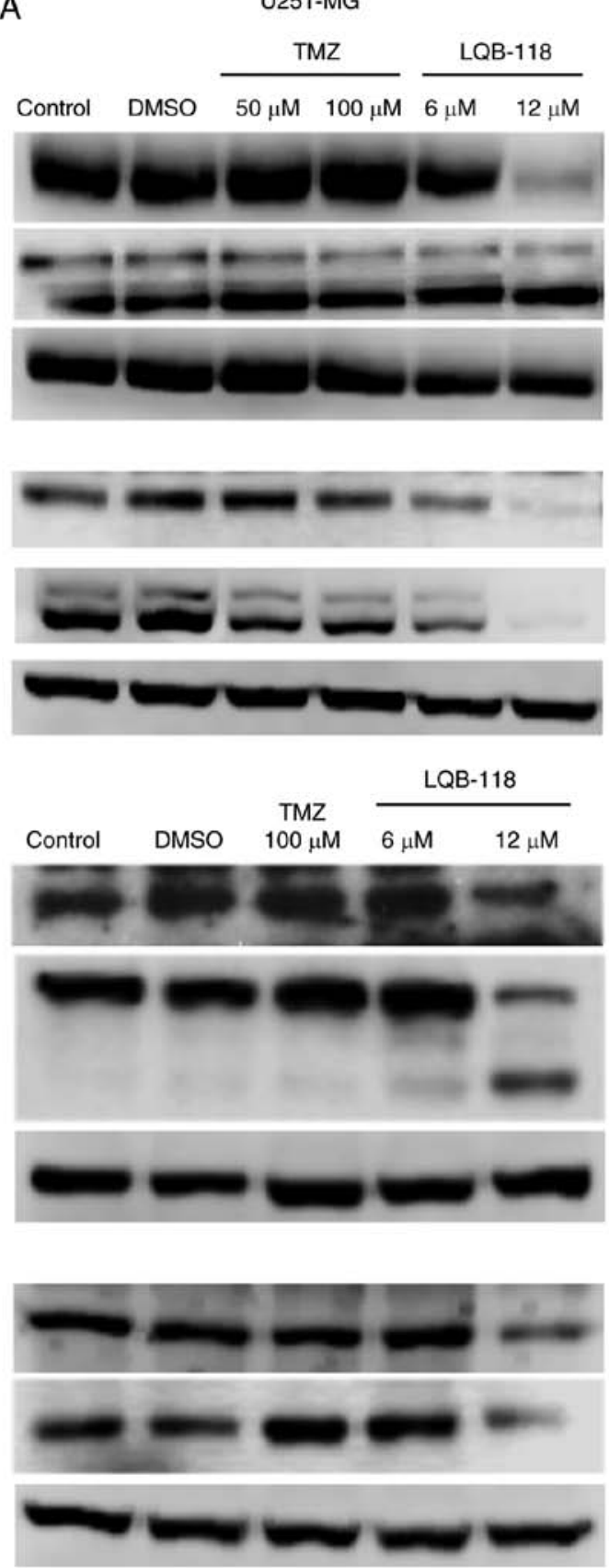

B

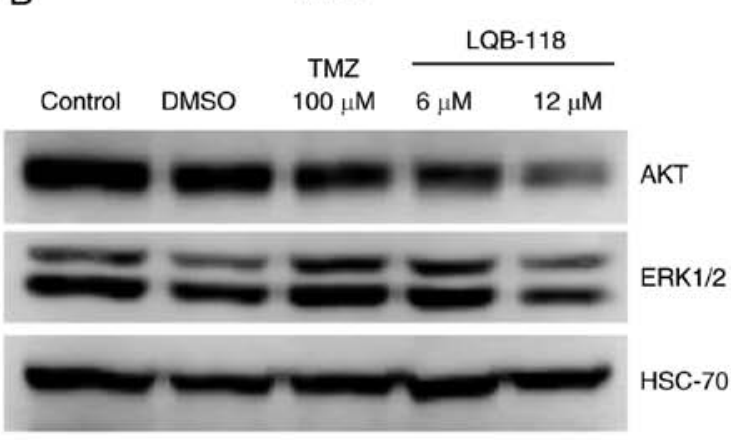

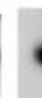

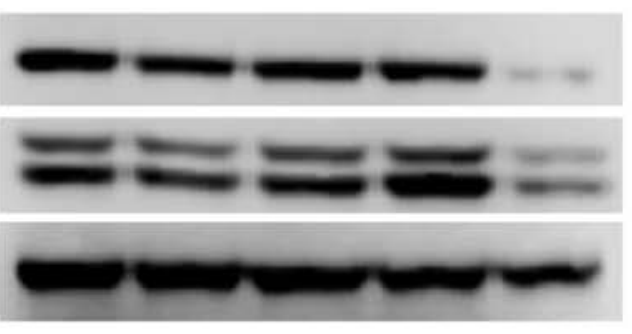

p-AKT

p-ERK $1 / 2$

HSC-70
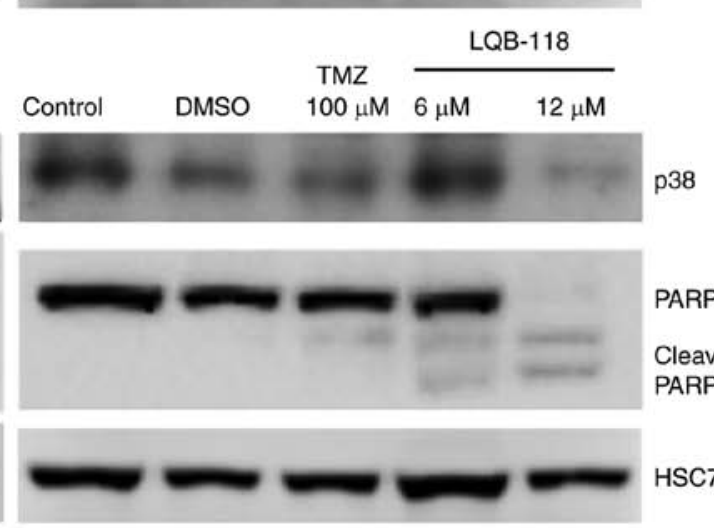

PARP

Cleaved PARP

HSC70

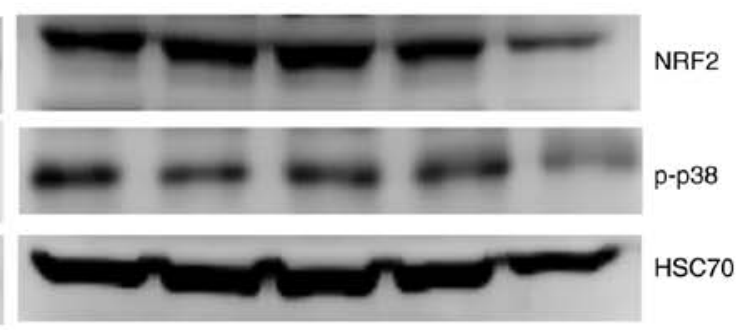

Figure 5. Effect of LQB-118 and TMZ on AKT and MAPK signaling pathways. Akt, p-Akt, ERK1/2, p-ERK1/2,p38, p-p38, NRF2 and PARP expression levels were analyzed after LQB-118 and TMZ treatment for $24 \mathrm{~h}$ in a monolayer culture of (A) U251-MG and (B) A172 cell lines as determined by western blotting. Images represent three independent experiments. TMZ, temozolomide.

intestine absorption (11). Corroborating the potential in crossing the BBB, LQB-118 is effective in cells overexpressing P-glycoprotein (Pgp) and multidrug resistance protein (MRP) with enhanced efflux pump activity $(7,12)$. These proteins are one of the most important components of BBB, protecting the brain from xenobiotics in physiological conditions. In the tumor context, the identification of modifications in BBB developed the concept of blood-brain tumor barrier (BBTB). The BBTB is characterized by angiogenesis, which generates abnormal leaky vessels and BBTB disruption allowing tumor infiltration in parenchyma among other alterations (32). LQB-118 is a potential drug to overcome BBTB protection, promoting an effective treatment and sensitizing tumor cells to conventional therapy. Accordingly, using an in vivo model of glioblastoma would be relevant to further confirm the potential of LQB-118 against this lethal malignancy.

Cell-based assays are important tools for novel compound identification. However, most assays used to assess the biological activity of novel compounds rely on traditional two-dimensional (2D) cell culture, having experimental limitations. The 3D architecture creates an environment with oxygen and nutrient gradients that ultimately alters gene expression resembling the tumor gene profile and microenvironment (33-35). The 3D cell culture system often exhibits different sensitivity to treatment, being better predictors of drug response (36). In the present study, LQB-118 maintained 

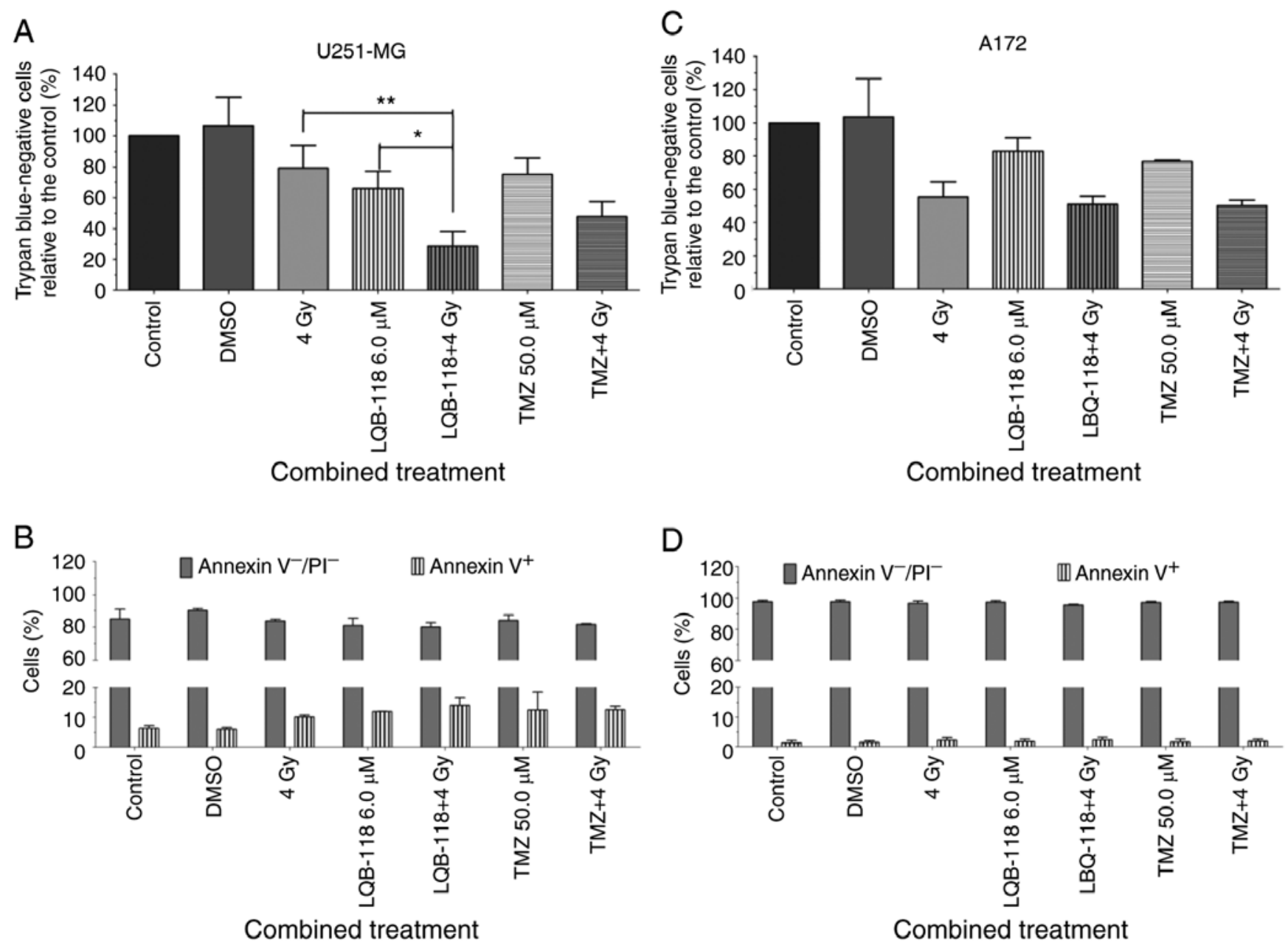

Figure 6. Effect of LQB-118 or TMZ combined with ionizing radiation on cell viability and cell death. (A) Percentage of U251-MG and (C) A172 trypan blue-negative cells relative to the control after treatment with LQB-118 or TMZ combined with ionizing radiation for $48 \mathrm{~h}$. Percentage of (B) U251-MG and (D) A172 Annexin V/PI-negative cells (viable cells) and Annexin V-positive cells (Annexin $\mathrm{V}^{+} / \mathrm{PI}^{-}+$AnnexinV $\mathrm{V}^{+} / \mathrm{PI}^{+}$) evaluated by flow cytometry. Mean of 3 independent experiments \pm SD. TMZ, temozolomide.

the cytotoxic effect observed in 2D cultures when assessed in spheroids. Furthermore, low doses of LQB-118 that did not reduce cell viability neither induce cell death, where able to reduce the migration of spheroids as observed in a 3D conformation. These data support the effect of LQB-118 exclusively on cell migration in the concentrations of choice. Migration, observed in a 3D conformation, partially mimics the ability of cells to invade the parenchyma since the assay requires cells to move in a semisolid medium without any chemoattractive factor to induce it. Furthermore, GBM invades the surrounding parenchyma, but does not evade the central nervous system, reinforcing the importance to evaluate migration capacity more than invasion by conventional assays since this tumor does not systemically metastasize. Therefore, migration inhibition is an important mechanism to impair parenchyma infiltration by tumor cells, the main reason for disease recurrence after tumor resection.

Previous literature has indicated an important role for mitochondrial metabolism in LQB-118 activity. The paranaphtoquinone moiety is reduced in the mitochondria and the resulting product can act like an alkylating agent or transfer electrons to molecular oxygen, producing ROS and inducing lipid peroxidation, in vitro $(5,10,12)$. Considering that an MTT assay evaluates mitochondrial enzyme activity, this could explain the intensified effect of LQB-118 observed in GBM. Corroborating our findings of Akt and MAPK pathway downregulation, our group demonstrated that FOXM1, FOXO3a and NF- $\mathrm{KB}$ transcriptional factors are regulated by LQB-118 in leukemic cell models $(6,8,13)$. Therefore, LQB-118 may be regulating the transcription factors by PI3K/AKT and MAPK pathway inhibition or may be regulating these pathways indirectly by endoplasmic reticulum (ER) stress due to protein misfolding culminating with apoptosis.

GBM is a highly heterogeneous disease and $\mathrm{p} 53$, receptor tyrosine kinase (RTK), PI3K/PTEN and MAPK are core pathways in gliomagenesis $(25,37)$. The selected cell lines present survival pathways constitutively activated at different levels, in which T98G and U251-MG cells are TP53 mutated whereas A172 is TP53 wild-type (23). Strategies that combine the inhibition of ERK and PI3K pathways, concurrently, have been demonstrated to be more efficient for glioma treatment $(38,39)$. Recent literature studies have demonstrated that the $\mathrm{p} 38 / \mathrm{NRF} 2$ axis is associated with TMZ resistance $(15,40)$. PI3K/AKT and MAPK inhibition and NFR2 knockdown was revealed to sensitize GBM cells to radiation and TMZ treatment $(15,38,40,41)$. The present study demonstrated that 
A

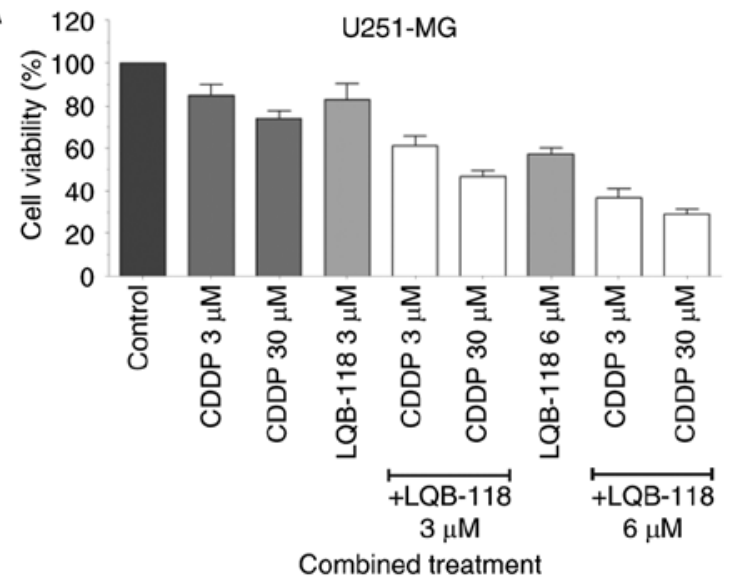

C

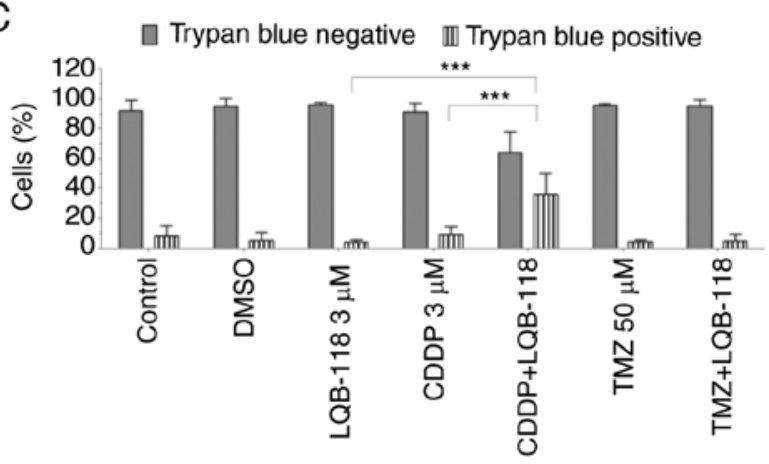

Combined treatment

E

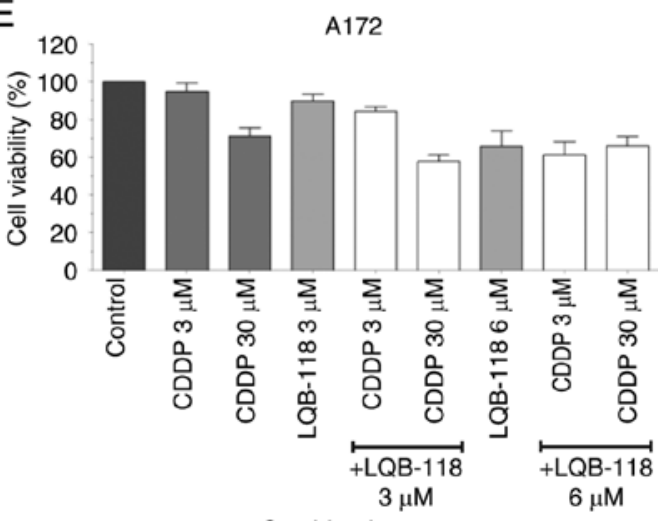

Combined treatment

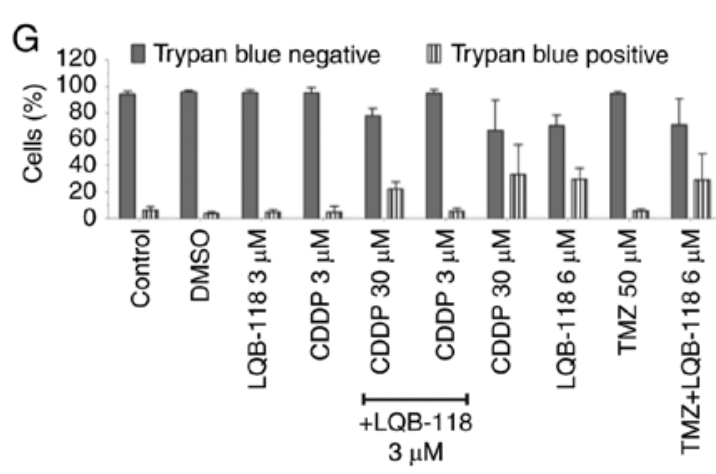

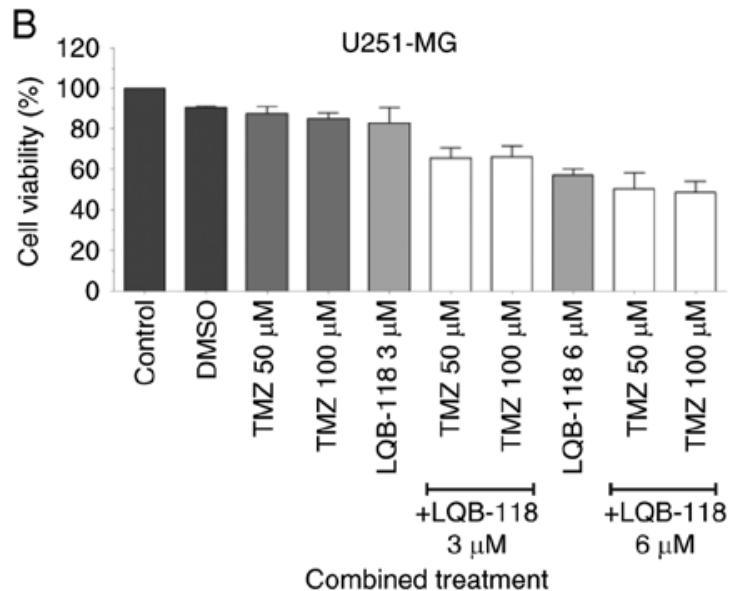

Combined treatment

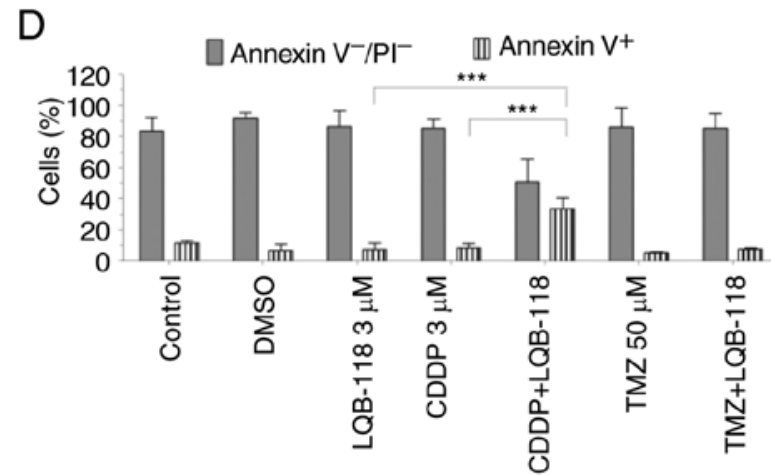

Combined treatment

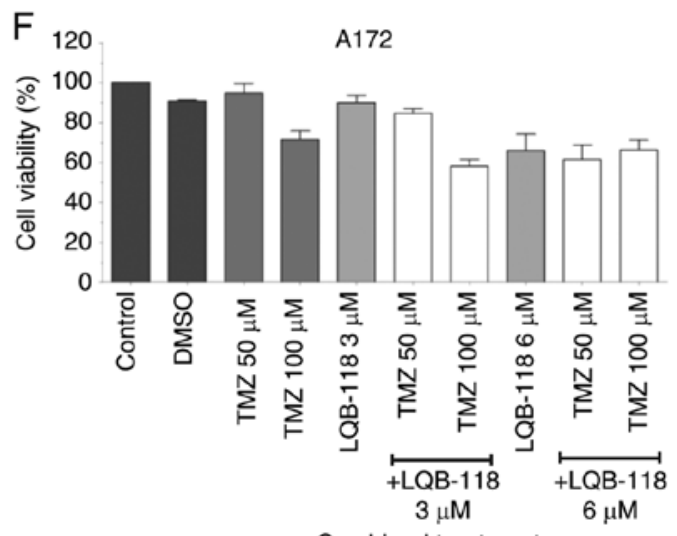

Combined treatment

$\mathrm{H}$

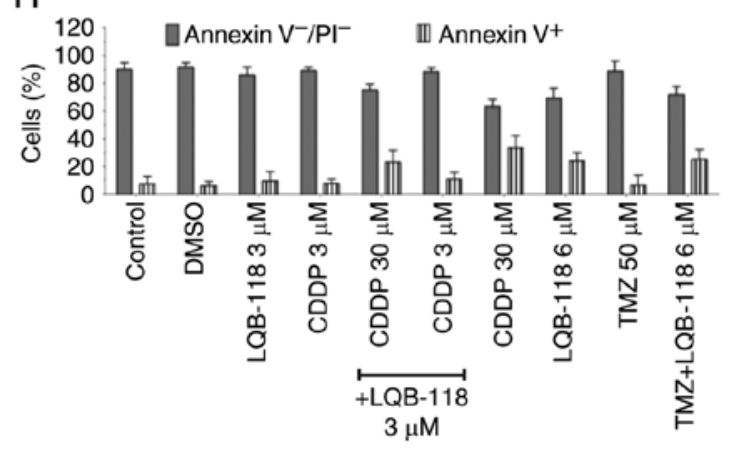

Combined treatment

Figure 7. Effect of LQB-118 combined with chemotherapeutic agents on cell viability and cell death. Combined treatment of LQB-118 with CDDP or TMZ in U251-MG and A172 cells for $48 \mathrm{~h}$. Percentage of U251-MG and A172 viable cells after treatment with LQB-118 combined with (A and E) CDDP and (B and F) TMZ as determined by MTT. Mean of three independent experiments \pm SEM. Percentage of trypan blue-negative and -positive cells in each treatment condition of (C) U251-MG cells and (G) A172 cells. Percentage of Annexin V/PI-negative cells (viable cells) and Annexin V-positive cells (Annexin $\mathrm{V}^{+} / \mathrm{PI}^{-}+$Annexin $\mathrm{V}^{+} / \mathrm{PI}^{+}$) in (D) U251-MG and (H) A172 cells as determined by flow cytometry. Mean of three independent experiments \pm SD. CDDP, cisplatin; TMZ, temozolomide. 
LQB-118 concurrently inhibited ERK, Akt and p38 activation, followed by reduction of NRF2 levels. These data indicate a potential effect of LQB-118 to sensitize cells to TMZ and radiation, mainly because there is no standard of care for GBM relapse. Therefore, it was determined whether LQB-118 combined with ionizing radiation or chemotherapy would be more effective, in vitro. The results demonstrated that LQB-118 treatment used with radiation reduced cell viability, while combination with low doses of cisplatin significantly enhanced cell death. This effect was cell line-dependent, demonstrating the importance of understanding the molecular basis of the disease for treatment decision. These data demonstrated that LQB-118 has a potent cytotoxic effect as monotherapy as well as combined with other antitumor agents, mainly cisplatin.

Collectively, the present data provided consistent evidence of the effectiveness of LQB-118 against GBM cell lines in a monolayer and 3D conformation. The cytotoxic effect was associated with the inhibition of PI3K and MAPK pathways, well described resistance pathways mutated in $60 \%$ of GBM cases (25). This is the first study to demonstrate the effect of LQB-118 in GBM as monotherapy and in combination, revealing a potential therapeutic alternative for patients resistant to standard protocol.

\section{Acknowledgements}

Authors would like to acknowledge Dr Vivaldo Moura-Neto from the Instituto Estadual do Cérebro (IEC), Rio de Janeiro, Brazil for kindly providing the studied cell lines. Also, the Laboratório de Diagnósticos por DNA - DECOL - IBRAG from UERJ for performance of STR profiling, the fellowships from the Ministério da Saúde/INCA that supported the work of authors PSB and FCCF and the Fundação de Amparo à Pesquisa do Rio de Janeiro (FAPERJ-nota 10) that supported the Master's degree of GHCG.

\section{Funding}

The present study was supported by funds from the Conselho Nacional de Desenvolvimento Científico e Tecnológico (CNPq-304565/2016-4) and the Fundação de Amparo à Pesquisa do Rio de Janeiro (FAPERJ; E-26/202-798/2017).

\section{Availability of data and materials}

The datasets used and/or analyzed during the present study are available from the corresponding author on reasonable request.

\section{Authors' contributions}

PSB was responsible for the study design, cell line monolayer experiments and manuscript writing. GHCG and FCCF performed western blotting and GMCL performed spheroid experiments. GPFL provided insights in the study design and revised it critically for important intellectual content. PRRC and CDN synthetized and provided LQB-118, revised the final version and agreed to be accountable for all aspects of the work. RCM was responsible for study conception and orientation. All authors critically revised and approved the final manuscript.

\section{Ethics approval and consent to participate}

The present study does not contain any studies with human participants or animals performed by any of the authors.

\section{Patient consent for publication}

Not applicable.

\section{Competing interests}

The authors declare that they have no competing interests.

\section{References}

1. Omuro A and DeAngelis LM: Glioblastoma and other malignant gliomas: A clinical review. JAMA 310: 1842-1850, 2013.

2. Stupp R, Mason WP, van den Bent MJ, Weller M, Fisher B, Taphoorn MJ, Belanger K, Brandes AA, Marosi C, Bogdahn U, et al: Radiotherapy plus concomitant and adjuvant temozolomide for glioblastoma. N Engl J Med 352: 987-996, 2005.

3. Weller M, van den Bent M, Tonn JC, Stupp R, Preusser M, Cohen-Jonathan-Moyal E, Henriksson R, Le Rhun E, Balana C, Chinot O, et al: European Association for Neuro-Oncology (EANO) guideline on the diagnosis and treatment of adult astrocytic and oligodendroglial gliomas. Lancet Oncol 18: e315-e329, 2017.

4. Dresemann G: Temozolomide in malignant glioma. Onco Targets Ther 3: 139-146, 2010.

5. Netto CD, da Silva AJ, Salustiano EJ, Bacelar TS, Riça IG, Cavalcante MC, Rumjanek VM and Costa PR: New pterocarpanquinones: Synthesis, antineoplasic activity on cultured human malignant cell lines and TNF-alpha modulation in human PBMC cells. Bioorg Med Chem 18: 1610-1616, 2010.

6. de Souza Reis FR, de Faria FC, Castro CP, de Souza PS, da Cunha Vasconcelos F, Bello RD, da Silva AJ, Costa PR and Maia RC: The therapeutical potential of a novel pterocarpanquinone LQB-118 to target inhibitor of apoptosis proteins in acute myeloid leukemia cells. Anticancer Agents Med Chem 13: 341-351, 2013

7. Maia RC, Vasconcelos FC, de Sá Bacelar T, Salustiano EJ, da Silva LF, Pereira DL, Moellman-Coelho A, Netto CD, da Silva AJ, Rumjanek VM and Costa PR: LQB-118, a pterocarpanquinone structurally related to lapachol [2-hydroxy-3-(3-met hyl-2-butenyl)-1,4-naphthoquinone]: A novel class of agent with high apoptotic effect in chronic myeloid leukemia cells. Invest New Drugs 29: 1143-1155, 2011.

8. Nestal de Moraes G, Castro CP, Salustiano EJ, Dumas ML, Costas F, Lam EW, Costa PR and Maia RC: The pterocarpanquinone LQB-118 induces apoptosis in acute myeloid leukemia cells of distinct molecular subtypes and targets FoxO3a and FoxM1 transcription factors. Int J Oncol 45: 1949-1958, 2014.

9. Martino T, Magalhães FC, Justo GA, Coelho MG, Netto CD, Costa PR and Sabino KC: The pterocarpanquinone LQB-118 inhibits tumor cell proliferation by downregulation of c-Myc and cyclins D1 and B1 mRNA and upregulation of p21 cell cycle inhibitor expression. Bioorg Med Chem 22: 3115-3122, 2014.

10. Martino T, Kudrolli TA, Kumar B, Salviano I, Mencalha A, Coelho MGP, Justo G, Costa PRR, Sabino KCC and Lupold SE: The orally active pterocarpanquinone LQB-118 exhibits cytotoxicity in prostate cancer cell and tumor models through cellular redox stress. Prostate 78: 140-151, 2018.

11. Cunha-Júnior EF, Martins TM,Canto-Cavalheiro MM, Marques PR, Portari EA, Coelho MG, Netto CD, Costa PR, Sabino KC and Torres-Santos EC: Preclinical studies evaluating subacute toxicity and therapeutic efficacy of LQB-118 in experimental visceral leishmaniasis. Antimicrob Agents Chemother 60: 3794-3801, 2016.

12. de Sá Bacelar T, da Silva AJ, Costa PR and Rumjanek VM: The pterocarpanquinone LQB 118 induces apoptosis in tumor cells through the intrinsic pathway and the endoplasmic reticulum stress pathway. Anticancer Drugs 24: 73-83, 2013.

13. de Faria FC, Leal ME, Bernardo PS, Costa PR and Maia RC: NFkB pathway and microRNA-9 and -21 are involved in sensitivity to the pterocarpanquinone LQB-118 in different CML cell lines. Anticancer Agents Med Chem 15: 345-352, 2015. 
14. Molina JR, Hayashi Y, Stephens C and Georgescu MM: Invasive glioblastoma cells acquire stemness and increased Akt activation. Neoplasia 12: 453-463, 2010.

15. Ma L,Liu J,Zhang X, Qi J, Yu W and Gu Y: p38 MAPK-dependent $\mathrm{Nrf} 2$ induction enhances the resistance of glioma cells against TMZ. Med Oncol 32: 69, 2015.

16. Jiang Z, Pore N, Cerniglia GJ, Mick R, Georgescu MM, Bernhard EJ, Hahn SM, Gupta AK and Maity A: Phosphatase and tensin homologue deficiency in glioblastoma confers resistance to radiation and temozolomide that is reversed by the protease inhibitor nelfinavir. Cancer Res 67: 4467-4473, 2007.

17. Friedrich J, Seidel C, Ebner R and Kunz-Schughart LA: Spheroid-based drug screen: Considerations and practical approach. Nat Protoc 4: 309-324, 2009.

18. Friedrich J, Eder W, Castaneda J, Doss M, Huber E, Ebner R and Kunz-Schughart LA: A reliable tool to determine cell viability in complex 3-d culture: The acid phosphatase assay. J Biomol Screen 12: 925-937, 2007.

19. Schneider CA, Rasband WS and Eliceiri KW: NIH Image to ImageJ: 25 years of image analysis. Nat Methods 9: 671-675, 2012

20. Chou TC: Drug combination studies and their synergy quantification using the Chou-Talalay method. Cancer Res 70: 440-446, 2010.

21. Chou TC: Theoretical basis, experimental design, and computerized simulation of synergism and antagonism in drug combination studies. Pharmacol Rev 58: 621-681, 2006

22. Ostermann S, Csajka C, Buclin T, Leyvraz S, Lejeune F, Decosterd LA and Stupp R: Plasma and cerebrospinal fluid population pharmacokinetics of temozolomide in malignant glioma patients. Clin Cancer Res 10: 3728-3736, 2004.

23. Ishii N, Maier D, Merlo A, Tada M, Sawamura Y, Diserens AC and Van Meir EG: Frequent co-alterations of TP53, p16/CDKN2A, p14ARF, PTEN tumor suppressor genes in human glioma cell lines. Brain Pathol 9: 469-479, 1999.

24. Shield K, Ackland ML, Ahmed N and Rice GE: Multicellular spheroids in ovarian cancer metastases: Biology and pathology. Gynecol Oncol 113: 143-148, 2009.

25. Cancer Genome Atlas Research Network: Comprehensive genomic characterization defines human glioblastoma genes and core pathways. Nature 455: 1061-1068, 2008.

26. Pelloski CE, Lin E, Zhang L, Yung WK, Colman H, Liu JL, Woo SY, Heimberger AB, Suki D, Prados M, et al: Prognostic associations of activated mitogen-activated protein kinase and Akt pathways in glioblastoma. Clin Cancer Res 12: 3935-3941, 2006.

27. Ostrom QT, Gittleman H, Truitt G, Boscia A, Kruchko C and Barnholtz-Sloan JS: CBTRUS statistical report: Primary brain and other central nervous system tumors diagnosed in the United States in 2011-2015. Neuro Oncol 20 (suppl 4): iv1-iv86, 2018.

28. Stupp R, Brada M, van den Bent MJ, Tonn JC and Pentheroudakis G; ESMO Guidelines Working Group: High-grade glioma: ESMO Clinical Practice Guidelines for diagnosis, treatment and follow-up. Ann Oncol 25 Suppl 3: iii93-iii101, 2014.
29. Lwin Z, MacFadden D, Al-Zahrani A, Atenafu E, Miller BA, Sahgal A, Menard C, Laperriere N and Mason WP: Glioblastoma management in the temozolomide era: Have we improved outcome? J Neurooncol 115: 303-310, 2013.

30. Salustiano EJ, Dumas ML, Silva-Santos GG, Netto CD, Costa PR and Rumjanek VM: In vitro and in vivo antineoplastic and immunological effects of pterocarpanquinone LQB-118. Invest New Drugs 34: 541-551, 2016.

31. da Silva AJ, Buarque CD, Brito FV, Aurelian L, Macedo LF, Malkas LH, Hickey RJ, Lopes DV, Noël F, Murakami YL, et al: Synthesis and preliminary pharmacological evaluation of new (+/-) 1,4-naphthoquinones structurally related to lapachol. Bioorg Med Chem 10: 2731-2738, 2002

32. van Tellingen $\mathrm{O}$, Yetkin-Arik B, de Gooijer MC, Wesseling $\mathrm{P}$, Wurdinger T and de Vries HE: Overcoming the blood-brain tumor barrier for effective glioblastoma treatment. Drug Resist Updat 19: 1-12, 2015.

33. Baharvand H, Hashemi SM, Kazemi Ashtiani S and Farrokhi A: Differentiation of human embryonic stem cells into hepatocytes in 2D and 3D culture systems in vitro. Int J Dev Biol 50: 645-652, 2006.

34. Barbone D, Van Dam L, Follo C, Jithesh PV, Zhang SD, Richards WG, Bueno R, Fennell DA and Broaddus VC: Analysis of gene expression in 3D spheroids highlights a survival role for ASS1 in mesothelioma. PLoS One 11: e0150044, 2016.

35. Nelson CM and Bissell MJ: Modeling dynamic reciprocity: Engineering three-dimensional culture models of breast architecture, function, and neoplastic transformation. Semin Cancer Biol 15: 342-352, 2005.

36. Hongisto V, Jernström S, Fey V, Mpindi JP, Kleivi Sahlberg K, Kallioniemi $\mathrm{O}$ and Perälä M: High-throughput 3D screening reveals differences in drug sensitivities between culture models of JIMT1 breast cancer cells. PLoS One 8: e77232, 2013.

37. Parsons DW, Jones S, Zhang X, Lin JC, Leary RJ, Angenendt P, Mankoo P, Carter H, Siu IM, Gallia GL, et al: An integrated genomic analysis of human glioblastoma multiforme. Science 321: 1807-1812, 2008.

38. Fan QW and Weiss WA: Targeting the RTK-PI3K-mTOR axis in malignant glioma: Overcoming resistance. Curr Top Microbiol Immunol 347: 279-296, 2010.

39. McNeill RS, Canoutas DA, Stuhlmiller TJ, Dhruv HD, Irvin DM, Bash RE, Angus SP, Herring LE, Simon JM, Skinner KR, et al: Combination therapy with potent PI3K and MAPK inhibitors overcomes adaptive kinome resistance to single agents in preclinical models of glioblastoma. Neuro Oncol 19: 1469-1480, 2017.

40. Li K, Ouyang L, He M, Luo M,Cai W, Tu Y, Pi R and Liu A: IDH1 $\mathrm{R} 132 \mathrm{H}$ mutation regulates glioma chemosensitivity through $\mathrm{Nrf} 2$ pathway. Oncotarget 8: 28865-28879, 2017.

41. Sato A, Sunayama J, Matsuda K, Seino S, Suzuki K, Watanabe E, Tachibana K, Tomiyama A,Kayama T and Kitanaka C: MEK-ERK signaling dictates DNA-repair gene MGMT expression and temozolomide resistance of stem-like glioblastoma cells via the MDM2-p53 axis. Stem Cells 29: 1942-1951, 2011. 